\title{
Encapsulation of thyme essential oil using electrospun zein fiber for strawberry preservation
}

\author{
Elham Ansarifar ${ }^{1}$ (I) and Farid Moradinezhad ${ }^{2 *}$ (D)
}

\begin{abstract}
Background: Strawberry is a nutrient-rich and important small fruit because of its high content of beneficial phytochemicals and several vitamins like vitamin C, vitamin E and vitamin B6. However, strawberry is highly perishable due to its susceptibility to mechanical damage, microbiological decay, and softening in texture. Recently, there has been an increasing interest in using various essential oils as natural food preservatives. Although, they have limited stability to exposure to high temperatures, light and oxygen, which could eventually affect sensory quality attributes. The electrospinning method is a simple and well-organized process that has been used to encapsulate essential oils. In this study, the effect of thyme essential oil (TEO) encapsulated into zein electrospun fiber film was assessed on extending the shelf life and preserving the quality of strawberry fruit during storage.

Findings: Results indicated that TEO presented potent antibacterial activity against Bacillus cereus, Escherichia coli and Aspergillus fumigatus. The scanning electron microscopy images of zein fiber had a linear shape, absence of beads, and smooth surface. The encapsulation efficiency (EE) of TEO in the zein fiber was about 75.23\%. Encapsulated TEO released at a slower rate than free TEO. The zein/TEO fibers (zein fiber film loaded with TEO) significantly ( $\left.p^{<} 0.05\right)$ decreased weight loss and maintained the anthocyanin content, firmness and color of the strawberries during storage. After 15 days of storage, weight loss reduced about 15\% and firmness was higher about 20\% in packed fruit with zein/TEO fibers compared to control.

Conclusions: Interestingly, after 15 days of cold storage, the strawberries firmness, appearance, and sensory evaluation, which are important quality factors from both postharvest and consumers'viewpoint, in zein/TEO fiber treatment were acceptable and had higher scores compared to the control. In conclusion, the present study demonstrated the benefits of incorporating TEO into zein films, which could play a significant role in the active packaging and preservation of strawberry fruits.
\end{abstract}

Keywords: Electrospun fiber, Fruit preservation, Anthocyanin, Active packaging, Fragaria ananassa

\footnotetext{
*Correspondence: fmn_46@yahoo.com; fmoradinezhad@birjand.ac.ir

${ }^{2}$ Department of Horticultural Science, Faculty of Agriculture, University

of Birjand, Birjand, Iran

Full list of author information is available at the end of the article
} 


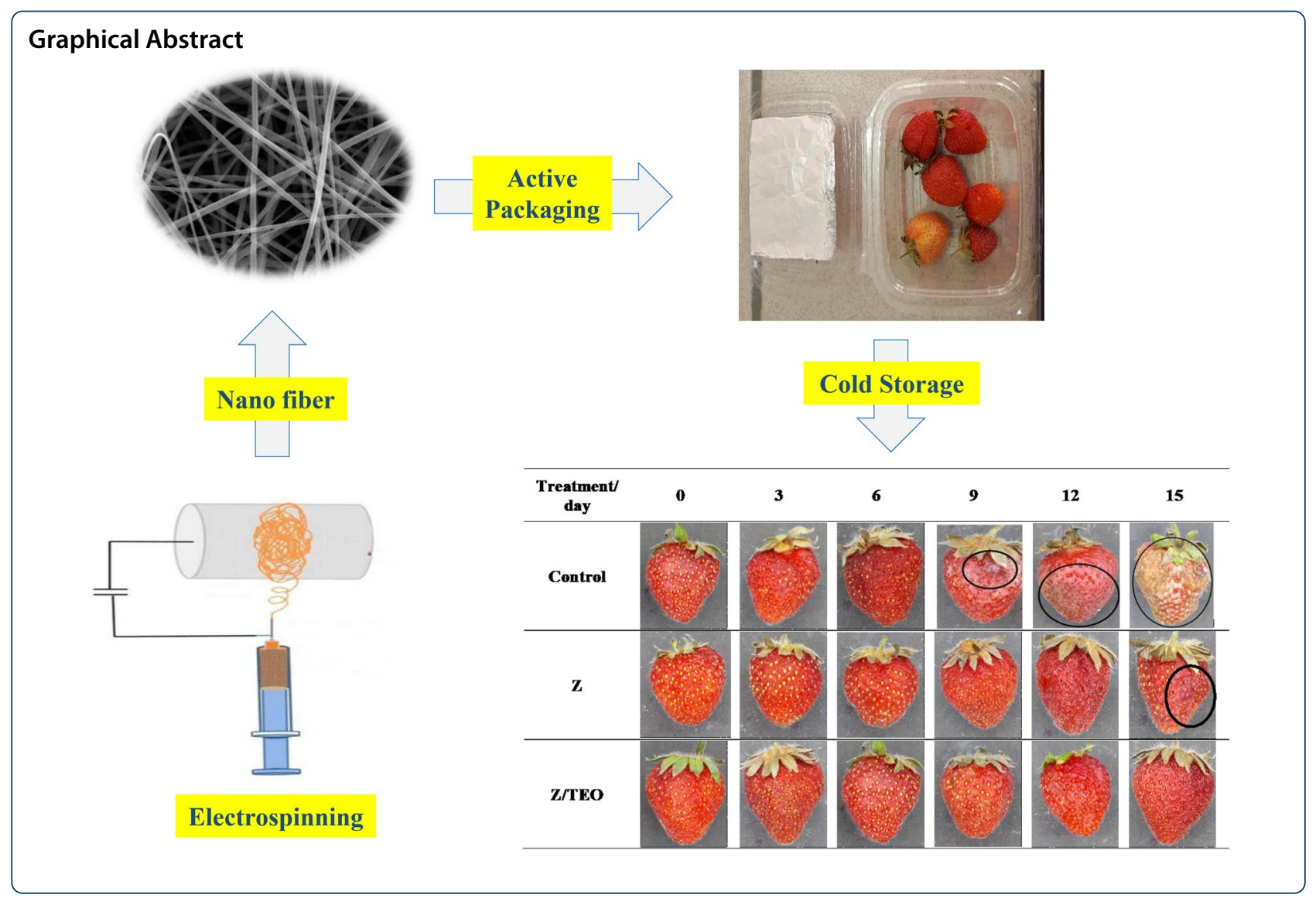

\section{Introduction}

Strawberry (Fragaria ananassa) is a nutrient-rich and important small fruit because of its high content of beneficial phytochemicals such as carotene, phenolic compounds, and several vitamins like vitamin $C$, vitamin $E$, thiamin, riboflavin, niacin, and vitamin B6 $[1,2]$. However, strawberry is highly perishable due to its susceptibility to mechanical damage, microbiological decay, and softening in texture [3].

Due to an increasing population and shifting dietary habits, the demand and processing of fruits have risen in recent decades. On the other hand, waste of fresh foods is becoming a significant problem from a nutritional, economic, and environmental perspective [2]. There are several techniques developed for slowing down the metabolic processes of fresh fruits and to reach long-term storage, such as modified atmosphere packaging, active packaging, and edible coating $[4,5]$.

Antimicrobial packaging, which is one such promising technology that impregnates the antimicrobial into the food packaging films and then releases it gradually to avoid microbial growth or pathogenic microorganisms and increase shelf life significantly [6]. Recently, application of natural antimicrobial compounds, especially essential oils, has shown much interest by consumers and the food industry. Essential oils contain antibacterial, antifungal and antioxidant properties, which are extracted from leaves, roots, or seeds of plants, so they are helpful in preventing of contaminants by pathogenic microorganisms [7]. Also, essential oils are highly volatile, unstable, and sensitive to oxygen, light and heat. Hence, encapsulation is an effective method to protect essential oils from environmental degradation and to mask their undesirable odor/flavor [6].

There are different methods for encapsulation of essential oils, such as emulsification, coacervation, spray drying, ionic gelation, nanoprecipitation, and liposome inclusion processes [8]. However, the electrospinning process is one of the most effective and also easy methods used to encapsulate essential oils [9]. Electrospinning is a fiber fabrication technique that is based on the deposition of an electrically charged single jet on a negatively charged ground collector [10]. The use of electrospun fibers in fabricating films and active packaging is of particular interest because of the controlled release of encapsulated contents $[2,11]$. Many studies have used electrospun fibers for fruit preservation like Shao et al. [2], fabrication tea polyphenols-loaded pullulan-CMC 
electrospun nanofiber; Zhang et al. [6], encapsulation of thymol in nanofiber via coaxial electrospinning; Li et al. [12], production of coaxial electrospun eugenol-loaded core-sheath PVP/shellac fibrous films; and Wen et al. [13], encapsulation of cinnamon essential oil in electrospun nanofibrous film for active food packaging.

Antioxidant and antimicrobial activity of Zataria multiflora Boiss. (Avishan-e Shirazi) was demonstrated against spoilage fungi and food microbiota [6, 7]. Ardekani et al. [14] evaluated electrospun poly(vinyl alcohol) with Zataria multiflora essential oil as a potential wound dressing. Lin et al. [15] studied the effect of electrospun thyme essential oil/gelatin nanofibers for active packaging against Campylobacter jejuni in chicken. Vafania et al. [16] evaluated the application of nanoencapsulation of thyme essential oil in chitosan-gelatin nanofibers by nozzle-less electrospinning to reduce nitrite in sausages.

Zein is a hydrophobic protein, which is becoming increasingly attractive to researchers in terms of highquality film-forming capabilities during electrospinning $[9,17]$. Shao et al. [10] evaluated the effect of zein nanofibers with cinnamaldehyde encapsulated for active packaging. Tucker et al. [18] enrichment of zen nanofiber assemblies for therapeutic delivery of Barij (Ferula gummosa Boiss) essential oil. Altan et al. [19] studied carvacrol-loaded electrospun fibrous film from zein for active food packaging.

In the current study, we encapsulated thyme essential oil (TEO) in zein (Z) fiber film using electrospinning. The effect of Zein/TEO fiber film on weight loss, firmness, TSS, anthocyanin content, color parameters, and sensory properties of strawberry during storage was explored.

\section{Materials and methods Materials}

Zein (Sigma, CAS Number 9010-66-6), thyme essential oil (Barij Co., Iran), glacial acetic acid (CAS Number 64-19-7) and all reagents were of analytical grade. The organic strawberries (Selva cultivar) were obtained from a farm located in Birjand, Iran.

\section{Antimicrobial activity of TEO}

The antimicrobial activity of TEO was evaluated using the following bacteria: Bacillus cereus (PTCC 1154) and Escherichia coli (ATCC 11775). Antifungal activity of TEO was tested on Aspergillus fumigatus (ATCC 1022). The lowest concentration in which the visible growth inhibited (MIC) was determined by the method of microbroth dilution assay [9].

\section{Preparation of electrospun fiber film}

Zein solution $30 \%(\mathrm{w} / \mathrm{v})$ was prepared using zein and glacial acetic acid, and then thyme essential oil (TEO) added to the polymer solution with a ratio of $4 \%(\mathrm{v} / \mathrm{w})$. Electrospun fibers were produced according to Ansarifar and Moradinezhad (2021) and Charpashlo et al. [20, 21] methods using electrospinning.

\section{Antibacterial activity of electrospun fiber}

To determine the antimicrobial activity of electrospun fiber against Gram-positive and Gram-negative bacteria, the disc diffusion method was used after the production of fibers. The samples (fiber) were cut into $10-\mathrm{mm}$ disc-shaped and then placed on Mullere Hinton Agar Plate (MHA) plates which had been already smeared with $1.5 \times 10^{8} \mathrm{CFU} / \mathrm{ml}$ colonies of Bacillus cereus (PTCC 1154 ) and Escherichia coli (ATCC 11775), and then incubated at $37^{\circ} \mathrm{C}$ for $24 \mathrm{~h} \mathrm{[22].}$

\section{Scanning electron microscopy (SEM)}

An electron microscope (Leo 1450VPSEM) was used to observe the morphology of fibers with an acceleration voltage of $20 \mathrm{kv}$ [9].

\section{Encapsulation efficiency TEO}

To determine entrapment efficiency (EE) of TEO loaded into fiber, the film (5 g) in $5 \mathrm{ml}$ aqueous ethanol solution (50\%) with a shaking speed at $120 \mathrm{rpm}$ for $10 \mathrm{~h}$. TEO concentration in the film was assessed by measuring absorbance at $278 \mathrm{~nm}$ [16]. The equation of the EE is as follows:

$$
E E(\%)=\frac{W_{i}}{W_{t}} \times 100,
$$

where $W_{i}$ is the actual TEO amount, and $W_{t}$ is the theoretical TEO amount.

\section{Release profile of TEO from zein fiber film}

To determine the release profile of TEO from zein fiber film, Zhang et al. method was used, and the amount of TEO was measured every $2 \mathrm{~h}$. The release curve of TEO encapsulated in fibers was determined according to the following method. $20 \mathrm{mg}$ of the fiber film in $20 \mathrm{ml}$ of ethanol (50\%) was stirred at a speed of $120 \mathrm{rpm}$ for $15 \mathrm{~min}$, and then the residual amount of TEO was measured by UV spectroscopy at $278 \mathrm{~nm}$ for $180 \mathrm{~h}$ [23]. The released TEO is equal to the difference between the TEO dissolved in ethanol and the initial amount of TEO in fiber film.

\section{Application to active packaging of strawberries}

In our experiment, representative fruit of strawberry was selected to evaluate the application of zein fiber with TEO in active food packaging. In the laboratory, strawberries screened for uniformity in size, color, appearance, and the absence of surface defects. Afterward, the fruits were washed with $0.1 \%$ sodium hypochlorite for 
$1 \mathrm{~min}$, and then randomly allocated to the polyethylene terephthalate (PET) containers with dimensions of $(11.5 \times 9.5 \times 6.2 \mathrm{~cm})$ and covered with their lids and kept in storage at $4 \pm 0.5^{\circ} \mathrm{C}$ and $85 \pm 5 \% \mathrm{RH}$ for 15 days. Treatments were 1 -control: the fruit packed in PET container without film on its lid; 2-zein: fruit packed in PET containers including zein fiber film on its lids; and 3-zein/ TEO: fruit packed in PET containers including zein fiber with TEO film on its lids. Strawberries were tested for physicochemical properties on the initial day and then at 3-day intervals.

\section{Assessment of fruits quality parameters}

Fruits were weighed by a digital balance (UWA-K-015, China). The difference between the initial and final weight is calculated as a percentage of the total weight loss. The fruit firmness was determined using a digital fruit hardness tester (FHT200, Extech Co., USA), fitted with a 2-mm-diameter cylinder probe. The surface color attributes of strawberries were determined with a colorimeter (TES 135-A, TAIWAN). $\mathrm{L}^{*}$, $\mathrm{a}^{*}$ and $\mathrm{b}^{*}$ parameters were recorded from two sides of each fruit [4]. Fruit was crushed, and pestle and juice collected. Total soluble solids (TSS) of juice were measured by a hand-held refractometer (Atago, Tokyo, Japan) at $20{ }^{\circ} \mathrm{C}$. Anthocyanin contents of strawberries measured according to the method described by Kirca et al. [24] using the $\mathrm{pH}$ differential. The results expressed as $\mathrm{mg} 100 \mathrm{~g}$ fresh weight. Sensory evaluation of samples was performed by ten trained members (five men and five women) on the 0,6 and 12th day of storage using a 9-point hedonic scale. Color, texture, taste, visual appearance and overall acceptance of strawberries were rated based on a ninepoint scale, $1=$ extremely bad and $9=$ extremely good (4.5 or higher $=$ acceptable) $[25]$.

\section{Statistical analysis}

An experiment with three repetitions for each storage time was conducted based on a completely randomized design using statistical software SPSS (IBM SPSS Statistics, Version 22, New York, USA). One-way analysis of variance ANOVA ( $p \leq 0.05$ significance level) and Duncan post hoc test was used to evaluate the difference between samples.

\section{Results and discussion}

\section{Antimicrobial activity of TEO and electrospun fiber}

The results of antimicrobial activity of TEO and electrospun fiber against fungi, Gram-positive and Gram-negative food-borne pathogens are presented in Table 1 . The $\mathrm{MIC}$ was $3.02 \pm 0.25,4.35 \pm 0.15$ and $1.06 \pm 0.32 \mathrm{mg} / \mathrm{ml}$ Bacillus cereus, Escherichia coli and Aspergillus fumigatus. The inhibition zone of zein and zein/TEO fiber
Table 1 Antimicrobial activity (MIC) of TEO and electrospun fiber

\begin{tabular}{llll}
\hline Microbe & MIC (mg/ml) & \multicolumn{2}{l}{$\begin{array}{l}\text { Inhibition zone of } \\
\text { fiber }(\mathbf{m m})\end{array}$} \\
\cline { 3 - 4 } & & Zein & Zein/TEO \\
\hline Bacillus cereus & $3.42 \pm 0.25$ & 0 & $15.54 \pm 0.24$ \\
Escherichia coli & $4.35 \pm 0.15$ & 0 & $8.12 \pm 0.52$ \\
Aspergillus fumigatus & $1.06 \pm 0.32$ & - & - \\
\hline
\end{tabular}

Data shown are the mean \pm standard error of three replicates

against Bacillus cereus and Escherichia coli is shown in Table 1. As expected, the zein fiber film as control group does not exhibit any antimicrobial properties without an aseptic region, while apparent inhibition rings are detected around zein/TEO. The inhibition zone of zein/ TEO fiber film against Bacillus cereus and Escherichia coli was $15.54 \pm 0.24$ and $8.12 \pm 0.52 \mathrm{~mm}$, respectively. Based on the obtained results, fungi were the most susceptible, Gram-positive bacteria showed moderate sensitivity and Gram-negative bacteria were the most resistant. There is a possibility that Gram-negative bacteria have resistance to lipophilic compounds such as essential oils because their impermeable outer membrane is hydrophilic [26]. Previous studies have shown that TEO is composed mainly of carvacrol and terpinene, which have effective antimicrobials [27]. Similarly, a study by Fatemi et al. [28] found that Staphylococcus aureus, Salmonella typhi and Escherichia coli were sensitive to the antimicrobial effect of TEO.

\section{Scanning electron microscopy (SEM)}

The SEM images of zein fiber had a uniform and homogenous shape, absence of beads, and smooth surface (Fig. 1). The diameter of zein fiber with and without TEO were $402.3 \pm 26.6 \mathrm{~nm}$ and $195.0 \pm 32.1 \mathrm{~nm}$, respectively. The results showed that fiber diameter increased $(p<0.05)$ when TEO was added to fibers. Possibly, this was due to a reduction in electrical conductivity, and thereby a reduction in elongation of polymer jet by applying voltage $[16,20]$. The increase in fiber diameter was observed similarly in different studies by adding cinnamic aldehyde $[9,10]$ and tomato extract $[29]$.

\section{Encapsulation efficiency $(\mathrm{EE})$ and release}

The EE of TEO in the zein fiber was about $75.23 \pm 16.4 \%$, under electrospinning conditions was used. The EE of thymol in polylactide-co-glycolide fiber achieved to be $90.3 \%$ [1]. The release rate of TEO in two different states (free and encapsulated) was investigated for $180 \mathrm{~h}$. The results for the control group clearly showed that TEO was released rapidly at room temperature and $60 \%$ of it after $80 \mathrm{~h}$. TEO encapsulated in zein 


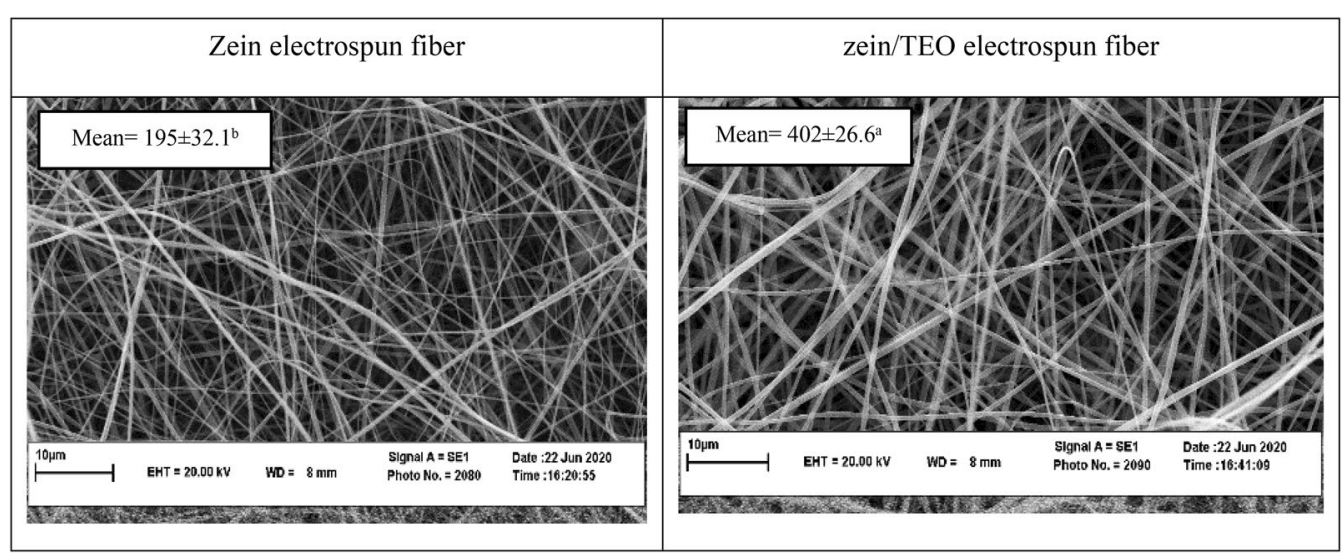

Fig. 1 SEM image of zein fibers without and with TEO (zein and zein/TEO)

fiber released into the atmosphere much more slowly, with only $65 \%$ of encapsulated TEO after $180 \mathrm{~h}$ (Fig. 2). Due to the formation of a core-shell structure by zein fiber film during electrospinning, TEO release was effectively controlled, as mentioned in similar works $[6$, 25]. Zhang et al. [6] reported that thymol evaporated rapidly within $19 \mathrm{~h}$ in the control group. Thymol encapsulated into fiber released into the atmosphere much more (36\% of it during $72 \mathrm{~h}$ ).

\section{Weight loss}

The fruit kept in the container with fiber had less weight loss compared to the control. All treatments significantly had lower weight losses compared to the control. The lowest weight loss (7.35\%) obtained in zein/TEO active packaging treatment (Table 2). Comparing all treatments, TEO released from the fiber slowed the ripening process more effectively and thus reduced the fruit weight loss significantly. Amal et al. [30] also mentioned that treated strawberries with TEO significantly reduced fruit weight

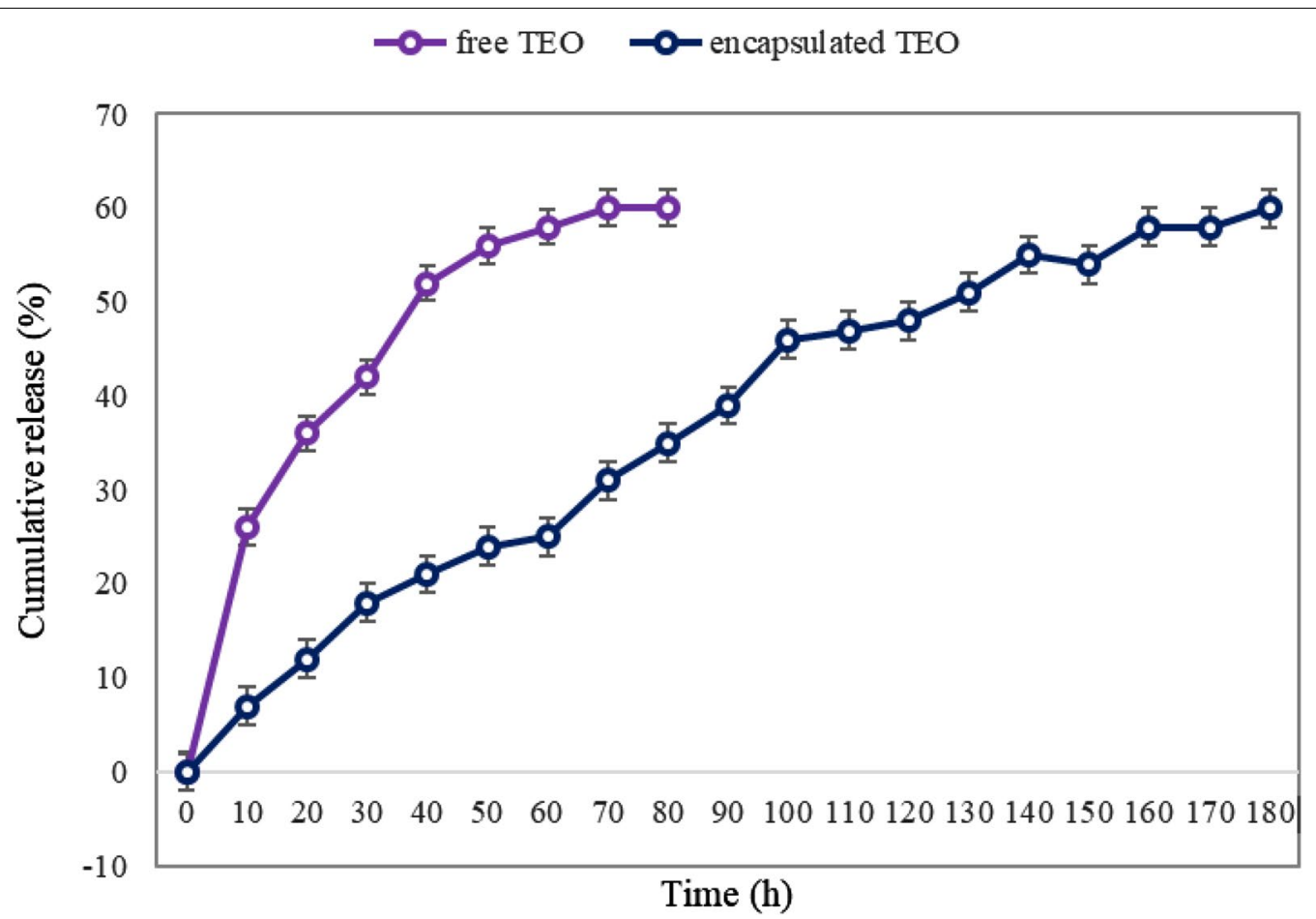

Fig. 2 Evaluation of the release of TEO free and encapsulated into zein fiber film 
Table 2 Effect of active packaging using zein and zein/TEO fiber on weight loss, firmness, total soluble solids, and anthocyanin content in strawberries stored at $4{ }^{\circ} \mathrm{C}$ for 15 days

\begin{tabular}{|c|c|c|c|c|}
\hline Active packaging treatment & Weight loss (\%) & Firmness (N) & TSS (\%) & $\begin{array}{l}\text { Anthocyanin } \\
(\mathrm{mg} 100 \mathrm{~g} \\
\text { FW) }\end{array}$ \\
\hline Control & $8.72 \pm 0.94^{\mathrm{a}}$ & $0.91 \pm 0.34^{b}$ & $7.86 \pm 0.80^{\mathrm{a}}$ & $182.2 \pm 31.45^{b}$ \\
\hline Zein & $7.46 \pm 0.87^{b}$ & $1.29 \pm 0.25^{\mathrm{a}}$ & $7.92 \pm 0.63^{\mathrm{a}}$ & $197.9 \pm 22.60^{a}$ \\
\hline Zein/TEO & $7.35 \pm 0.42^{c}$ & $1.34 \pm 0.25^{\mathrm{a}}$ & $7.84 \pm 0.53^{\mathrm{a}}$ & $192.1 \pm 18.30^{a}$ \\
\hline Significance & $* *$ & $* *$ & NS & $* *$ \\
\hline $\operatorname{LSD}(0.05)$ & 0.049 & 0.107 & 0.10 & 9.10 \\
\hline \multicolumn{5}{|l|}{ Storage time (day) } \\
\hline 0 & $0.0 \pm 0.00^{f}$ & $1.93 \pm 0.10^{\mathrm{a}}$ & $8.29 \pm 0.08^{\mathrm{ab}}$ & $245.1 \pm 2.88^{\mathrm{a}}$ \\
\hline 3 & $2.13 \pm 0.32^{e}$ & $1.20 \pm 0.23^{b c}$ & $8.60 \pm 0.16^{a}$ & $221.5 \pm 3.04^{b}$ \\
\hline 6 & $8.17 \pm 0.55^{d}$ & $1.29 \pm 0.27^{b}$ & $8.76 \pm 0.25^{\mathrm{a}}$ & $204.1 \pm 5.56^{c}$ \\
\hline 9 & $11.16 \pm 1.58^{c}$ & $1.05 \pm 0.24^{\mathrm{d}}$ & $7.88 \pm 0.17^{b}$ & $188.6 \pm 10.51^{\circ}$ \\
\hline 12 & $11.44 \pm 0.83^{b}$ & $1.07 \pm 0.16^{c d}$ & $7.22 \pm 0.21^{c}$ & $175.5 \pm 15.81^{\circ}$ \\
\hline 15 & $12.39 \pm 0.84^{\mathrm{a}}$ & $1.01 \pm 0.17^{d}$ & $6.52 \pm 0.31^{d}$ & $143.6 \pm 17.55^{\mathrm{e}}$ \\
\hline Significance & $* *$ & $* *$ & $* *$ & $* *$ \\
\hline LSD (0.05) & 0.060 & 0.131 & 0.12 & 14.46 \\
\hline $\begin{array}{l}\text { Interaction active packaging } \times \text { storage } \\
\text { time }\end{array}$ & $* *$ & $* *$ & $* *$ & $*$ \\
\hline
\end{tabular}

Data shown are the mean \pm standard error of three replicates

Means within columns with same letters are not significantly different

NS non-significant

loss compared to the control. There was a significant interaction between treatments and storage duration in terms of weight loss (Table 2). The fruit weight loss significantly increased as the storage time progressed (Fig. 3). The fruit weight loss occurred during storage due to its respiratory metabolic process. Similar to Dhital et al. [3] study on strawberry, the highest weight loss observed on the 15th day of storage in all treatments. However, the weight losses of packed fruits with fiber were significantly less than control fruits during the storage time. Generally, the lower weight losses lead to longer storage life and marketability of fresh fruits.

\section{Firmness}

Firmness is one of the important factors in determining the postharvest and market quality of strawberry fruit. All treatments significantly had higher firmness compared to the control. However, the highest firmness $(1.34 \mathrm{~N})$ was recorded in zein/TEO active packaging treatment (Table 2). The results suggested that TEO released from the fiber maintained the cell wall integrity of the fruit and reduced moisture loss and consistent with similar studies reported by Ranjan et al. [11]. As expected, the firmness of fruit decreased during the storage period. However, the firmness of all strawberries slowly reduced after 6 days of storage, and there were no significant differences on days 9, 12, and 15 (Fig. 3). There was a significant interaction between treatments and the storage time in terms of firmness (Table 2). The firmness of treated fruit remained higher than the control during storage period. In a recent study, Min et al. [31] reported prolonged softening of strawberry fruit and the loss of firmness being significantly reduced when packaged in TEO encapsulated in fibers with different composite films.

\section{Total soluble solids (TSS)}

TSS values remained steady in all active packaging treatments compared to the control. However, it declined gradually during the storage period (Table 2). The TSS percentage of strawberries significantly decreased after 9 days of storage. The reduction might be due to sugar metabolism during the respiratory process [11]. There was a significant interaction between treatments and storage time in terms of TSS (Table 2). After 15 days of storage, packed fruit in the container with fiber (zein/ TEO) was the most effective treatment in maintaining TSS (Fig. 3). This showed that after 15 days of storage, TSS loss was lower in zein/TEO treatment than the control. However, the TSS value first increased on day 3 and 6, and after that decreased (Fig. 3). The increased TSS is most likely due to the conversion of carbohydrates to sugars [31]. 


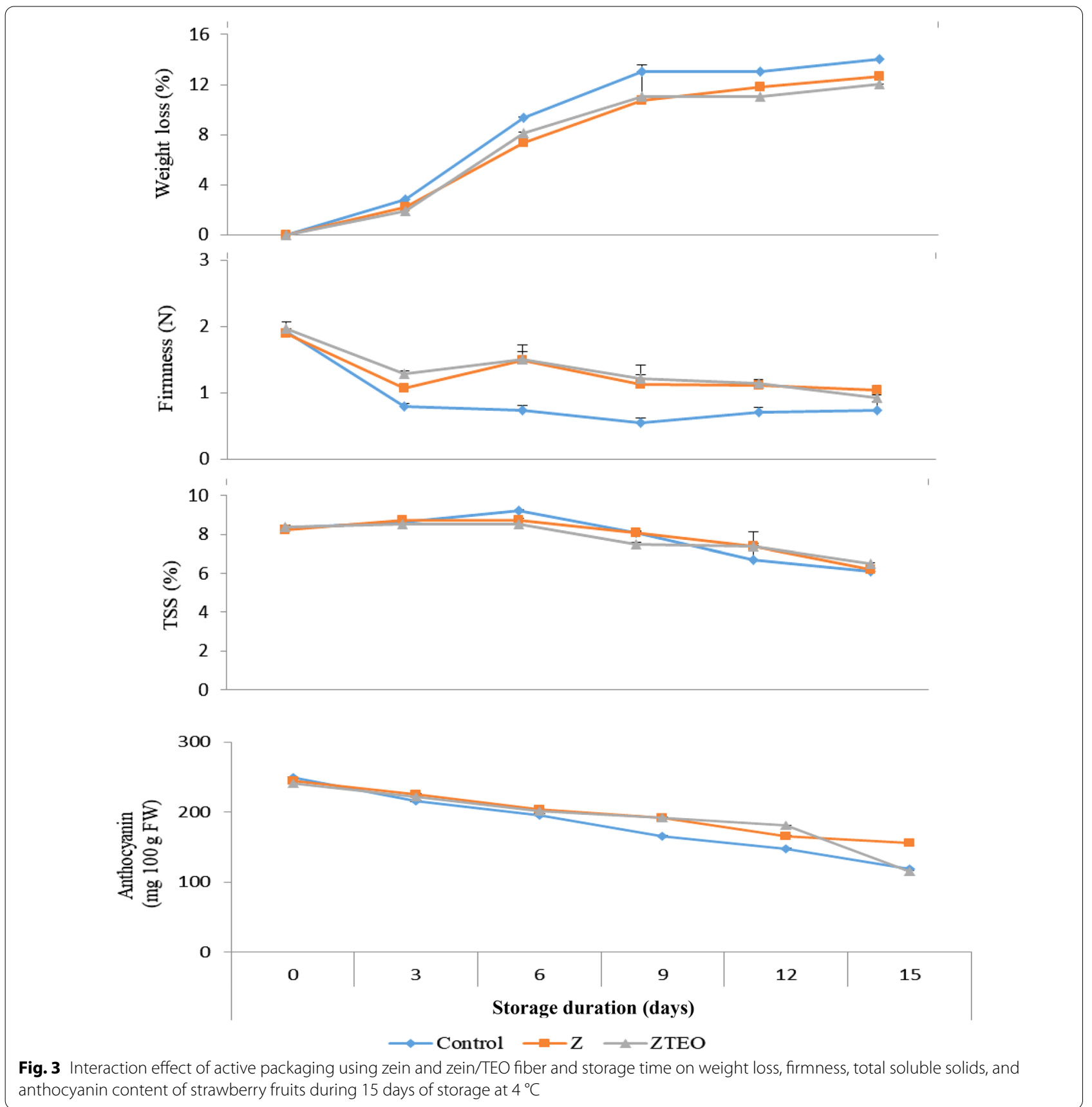

\section{Anthocyanin}

The total anthocyanin content of fruit was affected by both active packaging and storage time (Table 2). The results displayed that anthocyanin was significantly lower in control than the treated groups. The highest anthocyanin (197.9 mg $100 \mathrm{~g} \mathrm{FW)} \mathrm{was} \mathrm{found} \mathrm{in} \mathrm{zein} \mathrm{treatment,}$ however, all fiber treatments significantly maintained the anthocyanin content compared to the control. This result is in line with Li et al. [32] report, who stated that nano-polyethylene packaging inhibited anthocyanin accumulation in strawberries compared to polyethylene packaging. Anthocyanin content of fruits was significantly decreased during storage period from 245.1 (first day) to $143.6 \mathrm{mg} 100 \mathrm{~g} \mathrm{FW}$ (day 15) (Table 2). The interaction between treatments and storage duration also was significant (Table 2). The initial anthocyanin content was similar, and no statistically significant differences were observed between the packaging treatments and control 
(Fig. 3). However, after 9 days of storage, the anthocyanin content of control samples was significantly lower than fruit packed in active packaging. Previous studies [33] reported that the total anthocyanin content of strawberries decreased gradually during cold storage. They stated that low-temperature storage significantly reduced the anthocyanin content in strawberry fruit. The stability of anthocyanin can be affected by other factors like $\mathrm{pH}$, TA (titratable acidity), TSS, oxygen, and light [33]. Increased $\mathrm{pH}$ or TSS might adversely effect on the stability of anthocyanin $[3,30]$.

\section{Color attributes}

Lightness $\left(L^{*}\right), a^{*}$ and $b^{*}$ attributes of the fruit skin color were affected by both active packaging and storage period (Table 3 ). There was a significant decrease in $L^{*}$ and $b^{*}$ values with increase storage time for all treatments, while $a^{*}$ value increased. These changes showed darker red fruits during storage. Fruit stored in the container with fiber resulted in a redder color (higher $a^{*}$ value), while control had a lighter red color (lower $a^{*}$ value). The highest $L^{*}$ was observed in zein/TEO treatment. The results suggested that TEO released from the fiber maintained the lightness of fruit. These results agreed with those obtained by Dhital et al. and Amal et al. [3, 30], who stated that postharvest treatments of strawberry delayed fruit senescence in which the skin color was lighter than control fruit. There was

Table 3 Effect of active packaging zein and zein/TEO, and storage time on color properties of strawberry fruits stored at $4{ }^{\circ} \mathrm{C}$ for 15 days

\begin{tabular}{llll}
\hline $\begin{array}{l}\text { Active packaging } \\
\text { treatment }\end{array}$ & $\boldsymbol{L}^{*}$ & $\boldsymbol{a}^{*}$ & $\boldsymbol{b}^{*}$ \\
\hline Control & $36.87 \pm 3.91^{\mathrm{c}}$ & $30.05 \pm 2.68^{\mathrm{c}}$ & $20.20 \pm 3.54^{\mathrm{c}}$ \\
Zein & $39.17 \pm 2.91^{\mathrm{b}}$ & $31.33 \pm 2.68^{\mathrm{b}}$ & $22.73 \pm 2.28^{\mathrm{a}}$ \\
Zein/TEO & $39.77 \pm 2.75^{\mathrm{a}}$ & $32.44 \pm 1.93^{\mathrm{a}}$ & $21.66 \pm 2.80^{\mathrm{b}}$ \\
Significance & $* *^{*}$ & $*^{*}$ & $*^{*}$ \\
LSD (0.05) & 0.295 & 0.509 & 0.448 \\
Storage time (day) & & & \\
$\quad 0$ & $47.66 \pm 0.33^{\mathrm{a}}$ & $27.47 \pm 0.49^{\mathrm{f}}$ & $28.19 \pm 0.30^{\mathrm{a}}$ \\
$\quad 3$ & $40.95 \pm 1.61^{\mathrm{b}}$ & $36.06 \pm 1.19^{\mathrm{a}}$ & $24.71 \pm 1.04^{\mathrm{b}}$ \\
$\quad 6$ & $38.11 \pm 1.45^{\mathrm{c}}$ & $34.16 \pm 1.04^{\mathrm{b}}$ & $22.90 \pm 0.95^{\mathrm{c}}$ \\
$\quad 9$ & $37.05 \pm 1.40^{\mathrm{d}}$ & $31.12 \pm 1.56^{\mathrm{d}}$ & $19.12 \pm 0.71^{\mathrm{d}}$ \\
$\quad 12$ & $36.16 \pm 1.57^{\mathrm{e}}$ & $31.33 \pm 1.51^{\mathrm{c}}$ & $19.16 \pm 1.64^{\mathrm{d}}$ \\
$\quad 15$ & $35.74 \pm 1.59^{\mathrm{f}}$ & $29.77 \pm 2.00^{\mathrm{e}}$ & $17.32 \pm 1.70^{\mathrm{e}}$ \\
Significance & $*{ }^{*}$ & $* *$ & $* *$ \\
\hline LSD (0.05) & 0.361 & 0.624 & 0.549 \\
Interaction active packaging & $* *$ & $* *$ & $* *$ \\
$\times$ storage time & & & \\
\hline
\end{tabular}

Data shown are the mean \pm standard error of three replicates

Means within columns with same letters are not significantly different a significant interaction between packaging treatments and the storage period (Table 3, Fig. 4). The $L^{*}$ and $b^{*}$ values of treated fruit remained higher than the control during storage, while $a^{*}$ value was higher on day 3 and then decreased, as the storage time progressed. This is likely related to the reduction of anthocyanin content in strawberry fruit during storage.

\section{Sensory evaluation}

As the final consumer decides whether treated fruits are acceptable, sensory evaluation is required [25]. Results of sensory attributes (appearance, texture, color, taste, and overall acceptance) of strawberries were evaluated on the 6th and 12th days of storage. Significant effects of storage time and treatment were observed in all sensory attributes (Table 4). In the control group, strawberries showed signs of decay and were not generally accepted for consumption on 6th day of storage, but fruit packed in packaging include zein fiber that encapsulated with TEO had an acceptable appearance for marketing. The scores of color and texture were better in fruits packed with zein/TEO fiber than control samples on 12th day of storage. Overall, the strawberries' organoleptic and sensory properties improved through active packaging included essential oil as reported by previous studies [13] $[23,25]$. Similar to our results, in the study of Wen et al. [13] on strawberry, fruit packed with nanofilms encapsulated with cinnamon essential oil had the highest sensory scores in all sensorial evaluation attributes (appearance, taste, color, and odor) after 18 days of cold storage.

\section{Conclusion}

Based on the findings from this study, it was confirmed that TEO has potent antibacterial action against fungi, Gram-positive and Gram-negative food-borne pathogens. Furthermore, zein fiber containing TEO was fabricated through the electrospinning method. The EE of TEO in the zein fiber was about $75.23 \pm 16.4 \%$ and TEO encapsulated in zein fiber released into the atmosphere much more slowly, with only $65 \%$ of encapsulated TEO after $180 \mathrm{~h}$. Strawberries packed in packaging contain zein/TEO fiber maintained the quality and prolonged shelf life. Interestingly, after 15 days of cold storage, the fruit firmness, appearance and color, which are important quality factors from postharvest viewpoint, in zein/TEO fiber treatment were acceptable for market than control. 

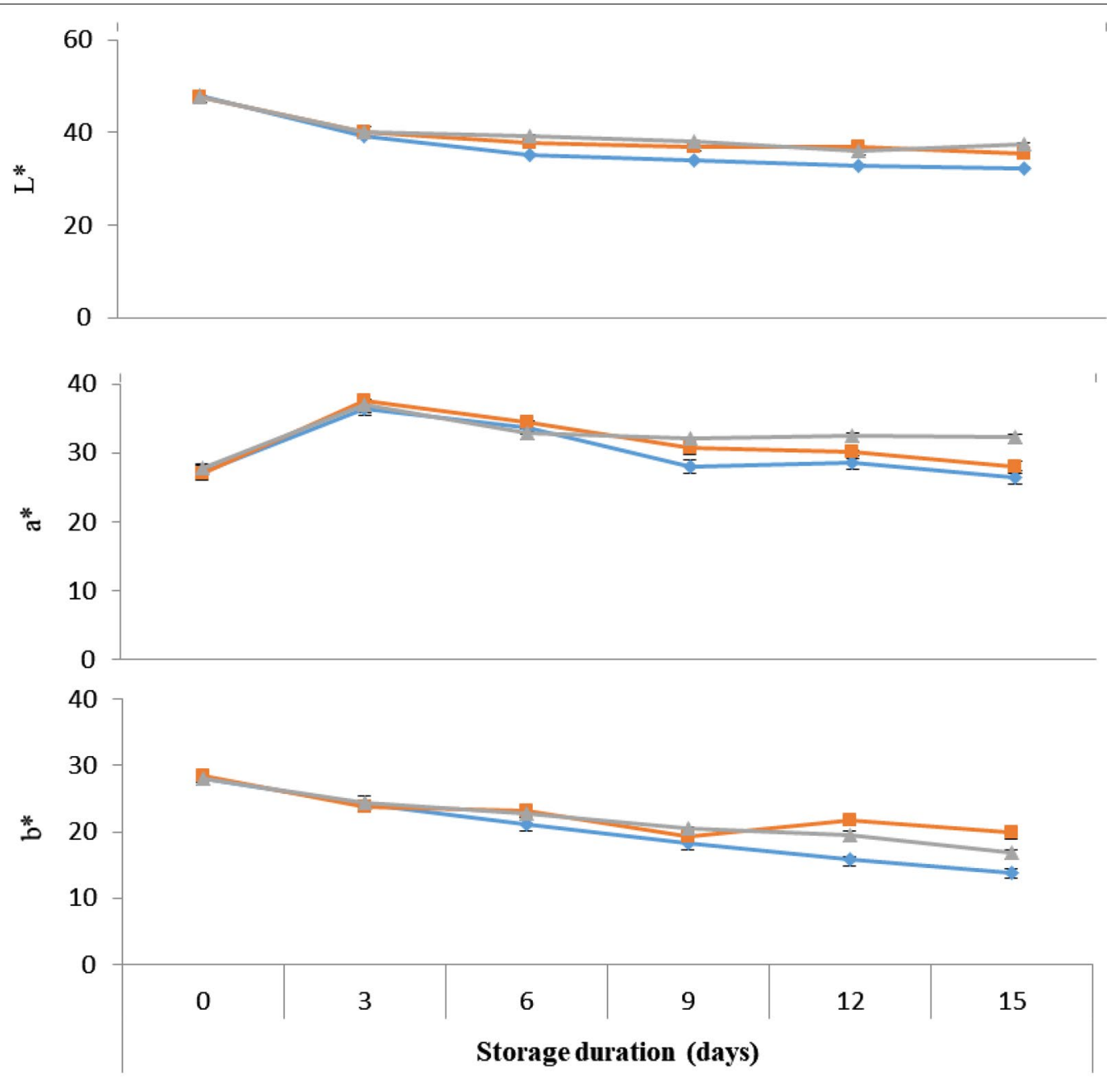

$\because$ Control $\quad-\mathrm{Z} \quad-$ ZTEO

Fig. 4 Interaction effect of active packaging using zein fiber and zein fiber loaded with thyme essential oil (zein/TEO) and storage time on color properties of strawberry fruits during 15 days of storage at $4{ }^{\circ} \mathrm{C}$ 
Table 4 Sensory attributes of packed fruits in packaging using zein fiber with and without TEO (zein and zein/TEO) during 12 days of storage at $4{ }^{\circ} \mathrm{C}$

\begin{tabular}{|c|c|c|c|}
\hline Day/treatment & 0 & 6 & 12 \\
\hline \multicolumn{4}{|l|}{ Color } \\
\hline Control & $8.10 \pm 0.13^{\mathrm{aA}}$ & $4.54 \pm 0.13^{\mathrm{bB}}$ & $3.22 \pm 0.13^{\mathrm{bcc}}$ \\
\hline Zein & $8.16 \pm 0.06^{\mathrm{aA}}$ & $5.00 \pm 0.12^{\mathrm{bB}}$ & $3.92 \pm 0.12^{b c}$ \\
\hline Zein/TEO & $8.13 \pm 0.13^{\mathrm{aA}}$ & $6.55 \pm 0.08^{\mathrm{aB}}$ & $4.40 \pm 0.11^{\mathrm{aC}}$ \\
\hline \multicolumn{4}{|l|}{ Texture } \\
\hline Control & $8.40 \pm 0.11^{\mathrm{aA}}$ & $4.51 \pm 0.08^{\mathrm{bB}}$ & $3.56 \pm 0.04^{c c}$ \\
\hline Zein & $8.35 \pm 0.02^{\mathrm{aA}}$ & $6.30 \pm 0.11^{\mathrm{aB}}$ & $4.53 \pm 0.07^{b c}$ \\
\hline Zein/TEO & $8.39 \pm 0.04^{\mathrm{aA}}$ & $6.50 \pm 0.21^{\mathrm{aB}}$ & $5.67 \pm 0.14^{\mathrm{aBC}}$ \\
\hline \multicolumn{4}{|l|}{ Taste } \\
\hline Control & $8.17 \pm 0.11^{\mathrm{aA}}$ & - & - \\
\hline Zein & $8.19 \pm 0.09^{\mathrm{aA}}$ & $5.52 \pm 0.12^{\mathrm{aB}}$ & $4.20 \pm 0.15^{b c}$ \\
\hline Zein/TEO & $8.15 \pm 0.04^{\mathrm{aA}}$ & $5.30 \pm 0.07^{\mathrm{aB}}$ & $4.40 \pm 0.15^{\mathrm{aBC}}$ \\
\hline \multicolumn{4}{|l|}{ Appearance } \\
\hline Control & $8.39 \pm 0.10^{\mathrm{aA}}$ & $3.54 \pm 0.12^{\mathrm{bB}}$ & $2.86 \pm 0.12^{\mathrm{CBC}}$ \\
\hline Zein & $8.29 \pm 0.14^{\mathrm{aA}}$ & $5.30 \pm 0.06^{\mathrm{aB}}$ & $4.25 \pm 0.11^{b C}$ \\
\hline Zein/TEO & $8.41 \pm 0.04^{\mathrm{aA}}$ & $6.17 \pm 0.07^{\mathrm{aB}}$ & $5.60 \pm 0.04^{\mathrm{aBC}}$ \\
\hline \multicolumn{4}{|c|}{ Overall acceptance } \\
\hline Control & $8.02 \pm 0.11^{\mathrm{aA}}$ & $4.07 \pm 0.10^{C B}$ & $2.73 \pm 0.08^{c C}$ \\
\hline Zein & $8.7 \pm 0.09^{\mathrm{aA}}$ & $5.63 \pm 0.07^{\mathrm{bB}}$ & $4.40 \pm 0.11^{b c}$ \\
\hline Zein/TEO & $8.10 \pm 0.10^{\mathrm{aA}}$ & $6.40 \pm 0.02^{\mathrm{aAB}}$ & $5.84 \pm 0.06^{\mathrm{aBC}}$ \\
\hline
\end{tabular}

Data shown are the mean \pm standard error of three replicates

${ }^{a-e}$ Different letters indicate significant difference between packaging treatments within each storage time

${ }^{A-E}$ Different letters indicate significant difference for the storage time for each packaging treatment

This study demonstrated the possibility of using zein/ TEO fiber for optimum performance in active packaging.

\section{Acknowledgements}

Special thanks to Prof. Majeed Mohammed for his valuable English editing of this report.

\section{Authors' contributions}

EA: methodology, investigation, data collection, formal analysis, writing and reviewing. FM: methodology, formal analysis, writing, reviewing and editing. Both the authors read and approved the final manuscript.

\section{Funding}

Authors would like to thank Iran National Science Foundation (INSF) gratefully for providing the financial support of this project, Contract Number 97022407.

\section{Availability of data and materials}

All data are presented in the manuscript.

\section{Declarations}

\section{Ethics approval and consent to participate}

The authors will follow the Ethical Responsibilities of Authors and COPE rules. On behalf of all co-authors, I believe the participants are giving informed consent to participate in this study.

\section{Consent for publication}

I, Elham Ansarifar give my consent for the submitted manuscript to be published in the Chemical and Biological Technologies in Agriculture.

\section{Competing interests}

The authors declare that they have no competing interests.

\section{Author details}

${ }^{1}$ Department of Public Health, Social Determinants of Health Research Center, School of Health, Birjand University of Medical Sciences, Birjand, Iran. ${ }^{2}$ Department of Horticultural Science, Faculty of Agriculture, University of Birjand,

Birjand, Iran.

Received: 19 August 2021 Accepted: 19 October 2021

Published online: 13 January 2022

\section{References}

1. Zhao L, Duan G, Zhang G, Yang H, Jiang S, He S. Electrospun functional materials toward food packaging applications: a review. Nanomaterials. 2020;10:1-31.

2. Shao P, Niu B, Chen H, Sun P. Fabrication and characterization of tea polyphenols loaded pullulan-CMC electrospun nanofiber for fruit preservation. Int J Biol Macromol. 2018;107:1908-14. https://doi.org/10.1016/j. ijbiomac.2017.10.054.

3. Dhital R, Mora NB, Watson DG, Kohli P, Choudhary R. Efficacy of limonene nano coatings on post-harvest shelf life of strawberries. LWT. 2018;97:124-34. https://doi.org/10.1016/j.Iwt.2018.06.038.

4. Moradinezhad F, Ansarifar E, Mohammadian MM. Extending the shelf life and maintaining quality of minimally-processed pomegranate arils using ascorbic acid coating and modified atmosphere packaging. J Food Meas Charact. 2020;14:3445-54. https://doi.org/10.1007/s11694-020-00591-1.

5. Yan Y, Duan S, Zhang H, Liu Y, Li C, Hu B, et al. Preparation and characterization of konjac glucomannan and pullulan composite films for strawberry preservation. Carbohydr Polym. 2020. https://doi.org/10.1016/j. carbpol.2020.116446.

6. Zhang Y, Zhang Y, Zhu Z, Jiao X, Shang Y, Wen Y. Encapsulation of thymol in biodegradable nanofiber via coaxial eletrospinning and applications in fruit preservation. J Agric Food Chem. 2019:67:1736-41.

7. Magdalena A, Pop A, Georgescu C, Turcus V, Olah NK, Mathe E. An overview of natural antimicrobials role in food. Eur J Med Chem. 2018;143:922-35

8. Ataei S, Azari P, Hassan A, Pingguan-Murphy B, Yahya R, Muhamad F. Essential oils-loaded electrospun biopolymers: a future perspective for active food packaging. Adv Polym Technol. 2020. https://doi.org/10.1155/ 2020/9040535

9. Karim M, Fathi M, Soleimanian-Zad S. Nanoencapsulation of cinnamic aldehyde using zein nanofibers by novel needle-less electrospinning: production, characterization and their application to reduce nitrite in sausages. J Food Eng. 2020;288:110140. https://doi.org/10.1016/j.jfood eng.2020.110140.

10. Shao $P$, Liu Y, Ritzoulis C, Niu B. Preparation of zein nano fibers with cinnamaldehyde encapsulated in surfactants at critical micelle concentration for active food packaging. Food Packag Shelf Life. 2019;22:100385. https://doi.org/10.1016/j.fpsl.2019.100385.

11. Ranjan S, Chandrasekaran R, Paliyath G, Lim LT, Subramanian J. Effect of hexanal loaded electrospun fiber in fruit packaging to enhance the post harvest quality of peach. Food Packag Shelf Life. 2020;23:100447. https:// doi.org/10.1016/j.fpsl.2019.100447.

12. Li Y, Dong Q, Chen J, Li L. Effects of coaxial electrospun eugenol loaded core-sheath PVP/shellac fibrous films on postharvest quality and shelf life of strawberries. Postharvest Biol Technol. 2020. https://doi.org/10.1016/j. postharvbio.2019.111028.

13. Wen P, Zhu DH, Wu H, Zong MH, Jing YR, Han SY. Encapsulation of cinnamon essential oil in electrospun nanofibrous film for active food packaging. Food Control. 2016;59:366-76.

14. Ardekani NT, Khorram M, Zomorodian K, Yazdanpanah S, Veisi H, Veisi H. Evaluation of electrospun poly (vinyl alcohol)-based nanofiber mats incorporated with Zataria multiflora essential oil as potential wound 
dressing. Int J Biol Macromol. 2019;125:743-50. https://doi.org/10.1016/j. ijbiomac.2018.12.085.

15. Lin L, Zhu Y, Cui H. Electrospun thyme essential oil/gelatin nanofibers for active packaging against Campylobacter jejuni in chicken. LWT. 2018;97:711-8. https://doi.org/10.1016/.l.wt.2018.08.015.

16. Vafania B, Fathi M, Soleimanian-Zad S. Food and bioproducts processing nanoencapsulation of thyme essential oil in chitosan-gelatin nanofibers by nozzle-less electrospinning and their application to reduce nitrite in sausages. Food Bioprod Process. 2019;116:240-8. https://doi.org/10 1016/j.fbp.2019.06.001.

17. Kayaci F, Uyar T. Electrospun zein nanofibers incorporating cyclodextrins. Carbohydr Polym. 2012;90:558-68. https://doi.org/10.1016/j.carbpol.2012. 05.078.

18. Tucker N. Enrichment of zein nanofibre assemblies for therapeutic delivery of Barije (Ferula gummosa Boiss) essential oil. J Drug Deliv Sci Technol. 2019. https://doi.org/10.1016/j.jddst.2019.101290.

19. Altan A, Aytac Z, Uyar T. Carvacrol loaded electrospun fibrous films from zein and poly(lactic acid) for active food packaging. Food Hydrocoll. 2018 https://doi.org/10.1016/j.foodhyd.2018.02.028.

20. Ansarifar $E$, Moradinezhad F. Preservation of strawberry fruit quality via the use of active packaging with encapsulated thyme essential oil in zein nanofiber film. Int J Food Sci Technol. 2021. https://doi.org/10.1111/ijfs. 15130.

21. Charpashlo E, Ghorani B, Mohebbi M. Multilayered electrospinning strategy for increasing the bioaccessibility of lycopene in gelatin-based sub-micron fiber structures. Food Hydrocoll. 2020. https://doi.org/10. 1016/j.foodhyd.2020.106411.

22. Zeinali T, Alemzadeh E, Zarban A, Khorashadizadeh M, Ansarifar E. Fabrication and characterization of jujube extract-loaded electrospun polyvinyl alcohol nanofiber for strawberry preservation. Food Sci Nutr. 2021. https://doi.org/10.1002/fsn3.2601.

23. Zhang $Y$, Zhang $Y$, Zhu Z, Jiao X, Shang Y, Wen Y. Encapsulation of thymo in biodegradable nano fiber via coaxial eletrospinning and applications in fruit preservation. J Agric Food Chem. 2019. https://doi.org/10.1021/ acs.jafc.8b06362.

24. Kirca A, Özkan M, Cemeroğlu B. Effects of temperature, solid content and $\mathrm{pH}$ on the stability of black carrot anthocyanins. Food Chem. 2007:101:212-8

25. Wen P, Zong MH, Linhardt RJ, Feng K, Wu H. Electrospinning: a novel nano-encapsulation approach for bioactive compounds. Trends Food Sci Technol. 2017;70:56-68.

26. Daneshmand F, Zare-Zardini H, Tolueinia B, Hasani Z, Ghanbari T. Crude extract from Ziziphus jujuba Fruits, a weapon against pediatric infectious disease. Iran J Pediatr Hematol Oncol. 2013;3:216-21.

27. Alehosseini A, Gómez-mascaraque LG, Ghorani B, López-rubio A. LWTfood science and technology stabilization of a saffron extract through its encapsulation within electrospun/electrosprayed zein structures. LWT Food Sci Technol. 2019;113:108280. https://doi.org/10.1016/j.lwt.2019. 108280.

28. Fatemi F, Asri Y, Rasooli I, Alipoor SD, Shaterloo M. Chemical composition and antioxidant properties of $y$-irradiated Iranian Zataria multiflora extracts. Pharm Biol. 2012;50:232-8.

29. İnanç Horuz T, Belibağlı KB. Nanoencapsulation by electrospinning to improve stability and water solubility of carotenoids extracted from tomato peels. Food Chem. 2018;268:86-93.

30. Amal SHA, El-Mogy MM, Aboul Anean HA, Alsanius BW. Improving strawberry fruit storability by edible coating as a carrier of thymol or calcium chloride. J Hortic Sci Ornam Plants. 2010;2:88-97.

31. Min T, Sun X, Yuan Z, Zhou L, Jiao X, Zha J, et al. Novel antimicrobial packaging film based on porous poly (lactic acid) nanofiber and polymeric coating for humidity-controlled release of thyme essential oil. LWT. 2021;135:110034. https://doi.org/10.1016/j.Iwt.2020.110034.

32. Li D, Ye Q, Jiang L, Luo Z. Effects of nano-TiO ${ }_{2}-$ LDPE packaging on postharvest quality and antioxidant capacity of strawberry (Fragaria ananassa Duch.) stored at refrigeration temperature. J Sci Food Agric. 2017:97:1116-23.

33. Octavia L, Choo WS. LWT_-food science and technology folate, ascorbic acid, anthocyanin and colour changes in strawberry (Fragaria ananassa) during refrigerated storage. LWT Food Sci Technol. 2017;86:652-9. https://doi.org/10.1016/.lwt.2017.08.049.

\section{Publisher's Note}

Springer Nature remains neutral with regard to jurisdictional claims in published maps and institutional affiliations.

\section{Submit your manuscript to a SpringerOpen ${ }^{\circ}$ journal and benefit from:}

- Convenient online submission

- Rigorous peer review

- Open access: articles freely available online

- High visibility within the field

- Retaining the copyright to your article

Submit your next manuscript at $\boldsymbol{\nabla}$ springeropen.com 